\title{
A importância da leitura na infância para a formação do sujeito leitor no contexto da realidade tecnológica digital
}

\section{Importance of reading in childhood for the training of the reader subject in the context of digital technological reality}

\author{
Caroline Kretzmann ${ }^{1}$ \\ Juliana Cristina Crespo Genaro² \\ Karina Pacheco dos Santos Vander Broock ${ }^{3}$
}

\begin{abstract}
Resumo
Este artigo aborda a importância da leitura na infância para a formação do jovem leitor, utilizando como ferramenta nesse processo as tecnologias digitais. Com a expansão da internet e o desenvolvimento de ferramentas e aplicativos, tem-se acesso a grande quantidade de textos e informações, o que pode permitir maior número de leituras. Mas isso não significa ler com mais qualidade, capacidade de análise e compreensão crítica. 0 Indicador de Alfabetismo Funcional (INAF) 2018 constatou que o brasileiro tem dificuldades para atingir o nível de proficiência em leitura e escrita. E o Programa Internacional de Avaliação de Estudantes (PISA) 2018 divulgou que o brasileiro tem baixa proficiência em leitura comparado com estudantes de outros países. Esse contexto levou à investigação de como o ensino e a aprendizagem de leitura na infância são importantes para a formação do jovem leitor, utilizando as tecnologias digitais como ferramentas nesse processo. Para tanto, foi realizada uma pesquisa bibliográfica, a partir da qual verificou-se que ler é uma atividade complexa de interação e produção de sentidos (SOLÉ, 1998; DELL'ISOLA, 2001; KOCH; ELIAS, 2006). E as estratégias que permitem a condução dessa prática precisam ser ensinadas, não sendo uma aquisição espontânea e individual. Assim, o cotidiano das crianças, inseridas ou não em processo escolar, precisa ser constituído por práticas de desenvolvimento dos multiletramentos, incluindo o digital (SOARES, 2002; RIBEIRO, 2006; XAVIER, 2011; COSCARELLI, 2017). Os nativos digitais apresentam certa facilidade com 0 uso de ferramentas tecnológicas, a partir das quais podem aperfeiçoar a leitura não apenas de signos linguísticos, mas também de recursos audiovisuais. Portanto, nos ambientes familiar e escolar, cabe o incentivo ao uso de programas, jogos e aplicativos de qualidade, com mediadores de leitura que conheçam e compreendam os recursos digitais, propiciando o uso construtivo por parte dos leitores em formação.
\end{abstract}

Palavras-chave: Leitura. Letramento digital. Formação do jovem leitor.

\begin{abstract}
This study addresses the importance of reading in childhood for the formation of young readers, using digital technologies in this process. With the expansion of the Internet and the development of tools and applications, the reader has access to a large number of texts and information, which can allow a greater number of readings. However, that does not mean better reading or ability to analyze and critically understand. The Functional Literacy Indicator (Indicador de Alfabetismo Funcional INAF) 2018 found that Brazilians face hardship to reach levels of proficiency in reading and writing, and the 2018 International Student Assessment Program (Programa Internacional de Avaliação de Estudantes - PISA) reported that Brazilians have lower reading literacy levels compared to students from other countries. This led to the investigation of how teaching and learning to read in childhood are important for the shaping of young readers, using digital technologies as tools. For this, the authors carried out bibliographical research, and found that reading is a complex activity of interaction and production of meaning (SOLÉ, 1998; DELL'ISOLA, 2001; KOCH; ELIAS, 2006). Also, the strategies that allow this practice to be conducted need to be taught and are not acquired spontaneous and individually. Thus, these children, whether they go to school or not, need to have practices for the development of multiliteracies, including the digital, in their daily life (SOARES, 2002; XAVIER, 2011;

\footnotetext{
${ }^{1}$ Mestre em Educação. Pontifícia Universidade Católica do Paraná, Curitiba, Paraná, Brasil. Orcid: https://orcid.org/00000001-5578-6475 E-mail: carolkretzmann@gmail.com.

2 Graduada em Letras Português - Inglês. Pontifícia Universidade Católica do Paraná, Curitiba, Paraná, Brasil. Orcid: https://orcid.org/0000-0002-3914-3709 E-mail: jgenaro21@hotmail.com.

${ }^{3}$ Mestre em Estudos de Linguagens. Universidade Tecnológica Federal do Paraná, Curitiba, Paraná, Brasil. Orcid: https://orcid.org/0000-0003-3239-3059 E-mail: karina.broock@gmail.com.
}

LínguaTec, Instituto Federal de Educação, Ciência e Tecnologia do Rio Grande do Sul, Bento Gonçalves 
RIBEIRO, 2016; COSCARELLI, 2017). Digital natives are used to technological tools, which can improve the reading not only of linguistic signs, but also of audiovisual resources. Therefore, in family and school environments, the use of good quality programs, games and applications should be encouraged, with reading mediators who know and understand digital resources, providing constructive use by readers in training.

Keywords: Reading. Digital Literacy. Young reader training.

\section{Introdução}

A capacidade de compreender e interpretar com autonomia textos orais e escritos é condição para o desenvolvimento pleno do cidadão na sociedade letrada. Crianças que, desde muito cedo, têm contato com instrumentos de leitura e recebem a intervenção de familiares e professores no processo que conduz à compreensão têm facilitado o acesso a essa prática social, o interesse por ela e a ampliação de habilidades de produção de sentidos.

A formação de leitores autônomos, capazes de construir significados em diferentes gêneros textuais e de aprender a partir do que foi lido, escutado ou discutido, desenvolvendo a capacidade de aprender a aprender depende de mediação, que deve ter início na infância, mesmo antes do processo de alfabetização. $O$ interesse pela leitura e 0 aprendizado de estratégias de compreensão leitora não nascem com o ser humano, mas requerem mediação que é iniciada na esfera familiar e se estende às esferas escolar e acadêmica.

Entretanto, ao verificar alguns dados no Relatório do Indicador de Alfabetismo Funcional (INAF - 2018), projeto do Instituto Paulo Montenegro - Ação Social do IBOPE e da ONG Ação Educativa, sobre letramento, podemos constatar que, no Brasil, ainda é evidente o percentual de brasileiros que apresentam dificuldades ao atingirem o nível de proficiência ${ }^{4}$ em práticas de leitura e escrita. A pesquisa efetuada considerou analfabetos funcionais, em 2018, aproximadamente 3 em cada 10 brasileiros que apresentam grande dificuldade para fazer uso da leitura, além da escrita e das operações matemáticas, também observadas. Essa avaliação é efetuada por meio de entrevistas com brasileiros de idade entre 15 e 64 anos, a quem são disponibilizados textos e contas matemáticas que fazem parte de ações cotidianas. O relatório também apresenta que, apesar da diminuição de analfabetos plenos ou brasileiros

\footnotetext{
4 "O indivíduo proficiente, no topo da escala de alfabetismo funcional, elabora textos de maior complexidade (mensagem, descrição, exposição ou argumentação) com base em elementos de um contexto dado e opina sobre o posicionamento ou estilo do autor do texto. É capaz de interpretar tabelas e gráficos envolvendo mais de duas variáveis, compreendendo a representação de informação quantitativa (intervalo, escala, sistema de medidas) e reconhecendo efeitos de sentido (ênfases, distorções, tendências, projeções). A pessoa proficiente também está apta a resolver situações-problema relativas a tarefas de contextos diversos, que envolvem diversas etapas de planejamento, controle e elaboração e que exigem retomada de resultados parciais e o uso de inferências" (INAF, 2018).
} 
em nível rudimentar de alfabetização, permanece estagnado, com apenas 12\%, o nível de alfabetizados proficientes (BRASIL, 2018).

Além disso, segundo relatório oficial do Instituto Nacional de Estudos e Pesquisas Educacionais Anísio Teixeira (INEP), o Programa Internacional de Avaliação de Estudantes (PISA - 2018) apontou que o brasileiro tem baixa proficiência em leitura em comparação com 78 países que participaram da avaliação. De acordo com os dados do relatório, "a média de proficiência dos jovens brasileiros em letramento em Leitura no Pisa 2018 foi de 413 pontos, 74 pontos abaixo da média dos estudantes dos países da OCDE (487)" (BRASIL, 2020, p. 68). Ainda, a edição revelou que, dos jovens de 15 anos avaliados, 50\% apresentaram fraco desempenho em leitura, abaixo do nível dois, o qual considera, em síntese, a identificação da ideia principal e a realização de inferências básicas em um texto.

Esses índices insatisfatórios na habilidade de ler dos jovens brasileiros torna-se um problema na medida em que a leitura é fundamental para que a pessoa possa produzir conhecimentos e viver em sociedade como um cidadão que tenha um amplo entendimento de mundo, seja comunicativo, independente, criativo e capaz de raciocinar criticamente (MARTINS, 2012).

Sobre a importância da leitura na infância para o desenvolvimento do jovem leitor, pesquisadores como Senhorini e Bortolin (2008) defendem que a criança, quando nasce, já responde a estímulos, observa tudo e aprimora os movimentos cognitivos adquiridos ainda no útero. E os primeiros e principais mediadores desse desenvolvimento são os pais, que podem motivar a percepção do bebê por meio de atividades que promovem a sua volta. Esses primeiros contatos com o mundo despertam diversas sensações e inicia a compreensão do que está ao redor (MARTINS, 2012). Essas percepções e assimilações de sentido são os primeiros passos para a leitura. Freire (2019) afirma que o ato de ler começa pela visão do mundo, pois isso é essencial para a compreensão da palavra. Na infância, antes do aprendizado formal da leitura, para que haja a sociabilização da criança e o aprimoramento da capacidade de compreender as atividades sociais de que faz parte, alguns elementos são importantes, como as brincadeiras, a ludicidade, fatores que promovem a aquisição de conhecimento, a empatia, o expressar sentimentos, interação e a evolução como ser humano.

Nesse contexto de aprendizado da leitura de mundo em práticas cotidianas e aquisição da palavra, a linguagem contemporânea é a digital, grande parte das crianças nascem internautas, pois, dentro do contexto social em que estão inseridas, existe celular, computador, vídeo games e tablets, brincadeiras continuam a existir como antigamente, mas agora há, além dos brinquedos tradicionais, os 
jogos on-line ${ }^{5}$, que despertam a curiosidade, bem como a criatividade das crianças, facilitando 0 aprendizado, como defende Coscarelli (2017). No entanto, é preciso levar em consideração que esse acesso aos meios digitais ainda não é universal, além disso, Pereira (2017) chama a atenção para 0 problema da inclusão digital. Segundo o autor, não basta garantir o acesso aos meios eletrônicos, a inclusão digital vai além do ato de digitar, mas envolve o domínio da "tecnologia para que, além de buscarmos a informação, sejamos capazes de extrair conhecimento" (PEREIRA, 2014, p. 17).

Ao abordar a geração Y (nascidos na década de 1990), Xavier (2011) ressalta que essa geração já apresenta certo domínio de ferramentas tecnológicas digitais. Dessa forma, afirma serem necessárias pesquisas que investiguem os impactos das tecnologias no aprendizado formal. Nas palavras do autor, é relevante compreender "como as máquinas digitais estão sendo usadas pelos estudantes para facilitar ou obstruir seu processo de aquisição de conhecimento e entender como eles estão interagindo com colegas e professores quando a relação é mediada por tais máquinas" (XAVIER, 2011, p. 5). Em pesquisa com nativos digitais de 9 a 14 anos de uma escola particular, o autor constatou que houve um aumento na frequência de práticas de leitura e produção de textos com a mediação das tecnologias digitais, em sua maioria, em situações de informalidade. Na atualidade, crianças e adolescentes que são letrados digitalmente se comunicam com mais veemência, têm efetuado um maior número de leitura em comparação com as crianças e adolescentes de gerações anteriores, que não dispunham de ferramentas tecnológicas digitais, como explica Xavier (2011), segundo o qual a criação de gêneros digitais, fixados em suportes multimidiáticos, facilita 0 ato da leitura. Por outro lado, o público investigado, ainda, segundo Xavier (2011), precisa aumentar o esforço intelectual para análise dos materiais lidos, pois armazena uma maior quantidade de informação ao efetuar a leitura nos meios digitais. Além disso, o autor questiona como as instituições de ensino podem utilizar as habilidades dos nativos digitais a favor da aprendizagem, uma vez que eles as empregam mais em situações de interação pessoal.

Santos e Silva (2019) afirmam que as tecnologias digitais estão inseridas no ambiente social das crianças de todas as idades, especialmente no âmbito de desenvolvimento da leitura e da escrita. Segundo essas pesquisadoras, a internet pode ajudar na formação da prática da leitura na infância, especialmente no desenvolvimento da análise crítica, mas salientam a importância de as crianças terem um acompanhamento para que as ferramentas tecnológicas digitais sejam utilizadas de maneira a agregar no processo de aprendizagem do ato de ler, formar e replicar o conhecimento por meio da compreensão do que leem.

\footnotetext{
5 É importante destacar que a Organização Mundial de Saúde (OMS) não recomenda o uso de telas para crianças com menos de 2 anos de idade (SOCIEDADE BRASILEIRA DE PEDIATRIA, 2019). Portanto, o aprendizado e o incentivo à leitura devem ser feitos com o uso de outras ferramentas nos dois primeiros anos de vida.
} 
Para Coscarelli (2017), com as mudanças nas formas de interação social, estão ocorrendo transformações na intercomunicação entre os indivíduos, nota-se, principalmente, que nos hábitos de leitura, há o contato com textos multimodais, ou seja, relação entre texto verbal, sons, imagens estáticas e dinâmicas. Ainda, a leitura realizada nos meios digitais pode despertar outras formas de compreensão e interpretação que trazem para o presente uma nova incumbência para formar o sujeito leitor.

Desse modo, esta pesquisa tem como objetivo apresentar como o ensino e a aprendizagem de leitura na infância são importantes para a formação do jovem leitor, utilizando as tecnologias digitais como ferramentas nesse processo. Para isso, trata da importância da leitura na infância para a formação do sujeito leitor; define como acontecem os processos de leitura nos meios digitais; e apresenta um levantamento de pesquisas realizadas sobre a tecnologia digital como ferramenta para a formação do jovem leitor.

\section{A importância da leitura na infância para a formação do sujeito leitor}

Ler um texto é uma ação que vai muito além de entender um conjunto de afirmações objetivas a serem decodificadas pelo leitor. Nas palavras de Dell'Isola (2001, p. 34), "leitura não é decodificação de sinais, reprodução mecânica de informações, respostas automáticas, irrefletidas, aos estímulos preestabelecidos, fornecidos pelo texto impresso". Ler é uma atividade bem mais complexa de interação e produção de sentidos, "que se realiza evidentemente com base nos elementos linguísticos presentes na superfície textual e na sua forma de organização, mas requer a mobilização de um vasto conjunto de saberes no interior do evento comunicativo" (KOCH; ELIAS, 2006, p. 11). Ao leitor não basta, portanto, conhecer o código linguístico e decodificá-lo, nem, como afirma Solé (2012), traduzir ou replicar o significado que 0 autor do texto quis Ihe dar. Mas espera-se que ele construa os sentidos do texto a partir de seus conhecimentos prévios e objetivos de leitura, bem como de sinalizações textuais dadas pelo autor. A leitura proficiente demanda, portanto, que o leitor dialogue com 0 autor, levantando questionamentos relacionados ao conteúdo do texto, concordando ou não com as ideias do autor, completando-as, adaptando-as, comparando-as com as de outros autores e fazendo inferências $(\mathrm{KOCH}$; ELIAS, 2006).

Essas ações estratégicas que permitem ao leitor conduzir e autorregular o processo de leitura, entretanto, precisam ser ensinadas, pois a aprendizagem da leitura não é uma aquisição espontânea e individual. Conforme defende Solé (1998, p. 172), "as estratégias de leitura não amadurecem, nem se desenvolvem, nem emergem, nem aparecem. Ensinam-se - ou não se ensinam - e se aprendem - ou 
não se aprendem". Nessa direção, Souza e Serafim (2012) declaram que o cotidiano da educação infantil precisa ser constituído por práticas pedagógicas direcionadas à leitura das crianças e ao fomento de seu desenvolvimento rumo não só aos processos de alfabetização, mas também de letramento.

Ainda, Freire (2011) afirma que ler é conhecer o mundo. Para ele, a leitura do mundo antecede a leitura da palavra e a compreensão do ato de ler acontece por meio de um processo contínuo de práticas que implicam percepções, as quais se transformam em memórias. 0 jovem leitor, quando estimulado a perceber o mundo que o rodeia (paisagens, lugares, objetos, pessoas, animais, entre outros), na infância, mesmo antes de ler palavras, desenvolve a capacidade de leitura e atribuição de sentido. E essas percepções, que ficam na memória, são as primeiras definições de leitura. Nesse sentido, para Martins (2012), as interações com o meio são fundamentais para o desenvolvimento da capacidade leitora, isto é, a autora afirma que se aprende a ler por meio da vivência.

Logo a compreensão de um texto não acontece apenas no momento em que a criança é alfabetizada. Como defendem Souza e Serafim (2012, p. 40): "o início da atividade leitora da criança deve começar bem antes de ela aprender de modo mais sistemático a língua escrita". Adotar esse posicionamento significa compreender familiares e professores da educação infantil como agentes de letramento: aqueles que ensinam a criança, desde muito cedo, a saber fazer uso social da leitura e da escrita, por meio de uma mediação voltada ao desenvolvimento da capacidade da compreensão leitora.

Souza e Serafim (2012) explicam que, mesmo sem ser capaz de ler alfabeticamente, a criança pode compreender uma história com base na escuta do texto e na leitura de imagens. Mas a mediação do adulto é importante. As autoras sugerem a leitura para a criança seguida de questionamentos que instiguem a interpretação das imagens, a relação entre elas e o texto ouvido, o entendimento vocabular e o levantamento de inferências, a fim de verificar a compreensão leitora. O reconto da história, segundo elas, é outra importante possibilidade a ser aplicada pelo mediador para levar a criança a essa compreensão.

Sobre essa mediação, Solé (1998) afirma ser de grande importância para o processo de aprendizagem da leitura na infância o acompanhamento de um adulto, dos pais ou da família. Para a pesquisadora, desenvolver com as crianças tarefas cotidianas conjuntas, tanto no lar quanto na escola de educação infantil, como a observação de uma lista de compras e a leitura de bilhetes encaminhados pela escola, não só estimulam a alfabetização, mas também auxiliam no desenvolvimento da linguagem em situações de uso real da língua e promovem a motivação inicial para a leitura.

Sobre a leitura de histórias, que é, sem dúvidas, a porta de abertura à alfabetização e ao letramento infantil, Soares (2020) ressalta que, ouvindo a leitura de histórias, as crianças ampliam o 
vocabulário e desenvolvem essa habilidade que posteriormente permitirá a leitura individual. Mas, para ela, é importante que o mediador também efetue com a criança a leitura de textos informativos curiosos; daqueles que orientam a prática de jogos; dos publicitários; jornalísticos; das histórias em quadrinhos, entre outros gêneros, sempre respeitando o nível de compreensão adequado a cada faixa etária.

Leal e Silva (2018) afirmam que as brincadeiras cotidianas da educação infantil e os jogos selecionados pelos professores desenvolvem o aprendizado da língua e estimulam a capacidade de interpretação, compreensão e produção de sentidos. Mencionam os jogos de faz de conta, em que as crianças utilizam a criatividade para fazer de conta que leem textos; e os jogos de construção, como as criações de palavras com letras, mesmo que combinadas de forma aleatória, mas que propiciam o contato com os símbolos.

Percebe-se, portanto, que são várias as possibilidades de inserir, desde cedo, as crianças no mundo dos multiletramentos ${ }^{6}$, tornando-as, por conseguinte, jovens capazes de ler e compreender com mais facilidade e prazer a multiplicidade semiótica de constituição de textos por meio dos quais a sociedade atual interage.

Foucambert (2014) especifica que a fase de preparação para a leitura autônoma acontece entre dois e oito anos, período em que a criança começa a conhecer códigos, sinais e desenhos do alfabeto fonético. No entanto, ressalta que esse processo se dá em etapas. Na primeira, deve haver uma mediação que propicie à criança participar da história contada, compreendendo seus elementos explícitos e realizando inferências, para que ela desenvolva a comunicação oral, descobrindo palavras novas. Na segunda etapa, a criança já pode ser incentivada a recontar essas histórias. Na terceira, pode reproduzir, por meio de ilustração, partes da história que ouviu. Essas etapas ativam o desenvolvimento das percepções áudio visuais e psicomotoras e propiciam uma maior sociabilização e contato com o mundo da assimilação da leitura, já ocorrendo um deciframento das palavras.

Ainda segundo Foucambert (2014), a faixa etária de oito a onze anos é o período em que a criança já é capaz de ler e pronunciar os vocábulos escritos, reconhecendo as palavras. Nessa fase, amplia o léxico, consulta dicionários e expande o campo da leitura até mesmo fora da escola. As placas de sinalização, as propagandas, os textos veiculados na televisão e nos jornais, ou seja, o acesso a diferentes gêneros e suportes possibilita e motiva a leitura. $O$ aprimoramento do ato de ler desenvolvese, portanto, no convívio social e no cotidiano da criança.

\footnotetext{
${ }^{6}$ Rojo (2010, p. 29) explica que o conceito de multiletramentos está associado a dois caminhos: "multiplicidade de linguagens e mídias nos textos contemporâneos e multiculturalidade e diversidade cultural".
} 
Como se pode perceber, para Foucambert (2014), a leitura é um processo de desenvolvimento contínuo do preparo à formação do sujeito leitor, e o aprimoramento desse processo depende, acima de tudo, da formação para ler produzindo sentidos. Por isso, crianças que, desde muito cedo, têm contato com instrumentos de leitura diversos têm facilitado o acesso à prática leitora e o interesse por ela. Pais e professores que têm o hábito de ler formam futuros leitores pelo exemplo e pela mediação que privilegia a compreensão, o debate (SOUZA; SERAFIM, 2012). E trata-se, aqui, de futuros leitores capazes de ler com autonomia e reflexão, para que não sejam apenas receptores de informações, mas transmissores de textos de qualidade e produtores de seus próprios textos, especialmente em uma rede digital que é atualizada diariamente.

\section{Como ocorrem os processos da leitura nos meios tecnológicos digitais}

Apesar de também considerar a leitura como um processo em que o leitor complementa os sentidos do texto, Chartier (1998) ressalta que esse caminho de atribuição de sentidos não é totalmente livre, pois o ato de ler também está condicionado ao tempo e ao espaço, bem como aos objetos e objetivos de leitura. Ou seja, transformações sociais e nos suportes demandarão novas ações do leitor ao construir seu percurso de leitura. Portanto, questiona-se quais seriam os procedimentos que o leitor das tecnologias digitais precisaria adotar para ler com proficiência nesse meio.

Para Santos e Silva (2019, p. 63), "o homem, ao longo de sua história, tem criado os mais diversos meios e ferramentas para melhor viver e se comunicar, todas proporcionam evolução e avanços". Essas pesquisadoras afirmam que, a partir da década de 1990, a internet expandiu-se com muita rapidez, e em 1995 esse serviço foi implantado no Brasil, ganhando força ao adotar o sistema de banda larga em 2000. Ainda, Santos e Silva (2019) explicam que os meios tecnológicos digitais dominam a era contemporânea, as pessoas utilizam, em especial, os aparelhos celulares móveis, computadores e tablets para o desenvolvimento social, cultural e educacional. Desse modo, o cotidiano é marcado pela interação gerada por meio da comunicação realizada pelas redes sociais. Essas ações são compreendidas por estudiosos da linguagem como próprias do letramento digital, definido por Ribeiro (2016, p. 163) como "práticas sociais e concepções para se poder realizar pesquisas na internet, acessar links de navegação, avaliar a credibilidade das fontes, compreender e produzir gêneros multimidiáticos, dentre outras".

Sobre a leitura em ambiente digital, Ribeiro (2006) defende que o processo de leitura do impresso para a tela não difere grandemente. Para ela, o texto é um "produto, objeto físico que ocupa lugar no 
espaço ou que se realiza elaborado em linguagem verbal, ainda que seja virtual, em diversos formatos", e é um processo, ou seja, vai "sendo lido e construído à medida que o leitor o 'desenrola', ou sendo reconfigurado de acordo com o repertório do leitor e sua interferência no texto-produto" (RIBEIRO, 2006, p. 17-18). Para a autora, tanto no impresso quanto no digital, o leitor precisa dominar condições mínimas de compressão e de leitura hipertextual. O que difere nos dois meios são as ações que ele precisa percorrer de acordo com o suporte de leitura.

Nessa direção, a autora compreende a leitura hipertextual como uma ação não-linear, o que "a mente faz de forma balística e natural na leitura de qualquer texto, seja ele oral, impresso ou digital, linear ou não-linear em sua aparência" (RIBEIRO, 2006, p. 20). Fica evidente que, para ela, portanto, o que diferencia texto e hipertexto, como produtos, são as funcionalidades dos suportes, cujas pistas são importantes para a atribuição de sentidos do leitor. Mas a leitura, seja em meios analógicos ou digitais, desenvolve-se sempre de modo complexo e não-linear.

Desse modo, a autora conclui que a navegação por um texto não se restringe ao suporte digital, mas está relacionada, também, à rota seguida pelo leitor em dado objeto de leitura, por exemplo, texto, gráfico, legenda, sumário, índice, conforme as escolhas feitas a partir de alternativas de caminho. Ela defende, portanto, a leitura digital mais como uma reconfiguração das práticas leitoras e dos modos de produção e publicação de textos segundo alternativas do novo suporte do que verdadeiramente uma novidade.

Ao defender o uso de jogos on-line no ensino de leitura e escrita, Ribeiro (2016) afirma que 0 suporte digital exige do leitor, além das habilidades de interpretação e compreensão textual, 0 conhecimento de recursos de navegação, a exemplo dos links, abas, janelas e ícones; a opção pela leitura linear ou acessando links; a percepção da multimodalidade; bem como a competência de integração de todas as categorias de signos para a constituição do sentido.

Soares (2002, p. 146), por sua vez, diferencia o letramento tradicional do letramento digital, afirmando que as práticas de leitura e escrita na cibercultura "conduzem a um estado ou condição diferente daquele a que conduzem as práticas de leitura e de escrita quirográficas e tipográficas". Para a autora, os novos espaços em que os textos circulam irão condicionar a relação entre autor-texto-leitor de forma mais abrangente. Nessa mesma direção, ao abordar o desenvolvimento do letramento digital, Xavier (2011) declara que, com a evolução nos processos tecnológicos digitais, os indivíduos tornam-se letrados digitais independentemente das atividades propostas pelas escolas, pois, desde cedo, acessam aparelhos tecnológicos em casa, então a aquisição desse letramento torna-se natural como andar e falar. 
Acredita-se, entretanto, que a mediação docente é necessária para que o estudante aprenda a selecionar e consumir informações de qualidade, além de construir e compartilhar conteúdos nas redes digitais. Concorda-se com Coscarelli (2017), que defende ser necessário inserir, no ambiente escolar, uma linha pedagógica que identifique o universo multimidiático e multissemiótico e que não fique restrita apenas à cultura do impresso. Para incluir o letramento digital nas escolas, ela esclarece que é necessário trabalhar com textos de diferentes mídias digitais, motivar a interação entre professor, estudante, escola e comunidade por meio de novas linguagens digitais e, principalmente, capacitar os professores com as novas formas de ensino. $E$ destaca que essa inovação não se reduz à mera inserção de tecnologias digitais a um modelo pedagógico conservador, mas atende a nova cultura de aprendizagem decorrente da atual sociedade da informação: a formação de sujeitos capazes de construir conhecimento e pensamento crítico e criativo. Para isso, é fundamental que os docentes estejam em atualizações constantes, repensem o modelo de sala de aula tradicional, reconfigurem conceitos e práticas, sendo capazes de explorar os recursos tecnológicos digitais para a realização de atividades interativas e desafiadoras.

Abordando mais especificamente as maneiras de trabalhar a leitura em meios digitais para formar leitores, Coscarelli (2017) apresenta que uma delas é efetuar várias leituras sobre um tema por meio da navegação digital. Para isso, a pessoa precisa ter um conhecimento mais amplo de como as interfaces digitais se organizam e contar com o auxílio de um mediador. Segundo Santos e Silva (2019), para que o indivíduo aprenda a ler utilizando os processos tecnológicos digitais, é necessário que exista uma interação entre escola-aluno-comunidade, incluindo o contexto social, para que haja uma motivação dentro e fora da escola.

Os pressupostos apresentados indicam a importância de pesquisas que investiguem como as tecnologias digitais podem reconfigurar as práticas linguísticas, bem como qual é o papel da mediação do professor ao selecionar ferramentas que efetivamente contribuam para o aprendizado do jovem leitor. Dessa forma, na sequência, serão apresentados estudos com sugestões de trabalho com práticas de leitura, na infância, mediadas pelas ferramentas digitais.

\section{A tecnologia digital como ferramenta para a formação do jovem leitor}

A formação do jovem leitor, especificamente no desenvolvimento do letramento digital, é abordada por diversos pesquisadores que apresentam sugestões de trabalho com a leitura na aprendizagem formal e familiar. Nesse sentido, ao tratar das relações entre infância, brincadeira e tecnologia, Gomes (2016) explica que, por meio do lúdico, a criança tem acesso à cultura; portanto, as 
brincadeiras podem e devem ser usadas no processo formativo infantil tanto no âmbito familiar quanto no escolar.

Os tipos de brincadeira e os locais onde são realizadas sofrem influência do contexto históricosocial de que fazem parte. Os jogos eletrônicos, o videogame, o MP4, o celular, o tablet, entre outros representam a virtualização do lúdico. As crianças nascidas na era digital se apropriam dos brinquedos eletrônicos e das tecnologias da informação e comunicação (TICs) sem temer os botões, as luzes, as cores, os movimentos e as novidades que trazem. Aprendem com a interatividade, ludicidade e fantasia proporcionadas tanto por brincadeiras tradicionais quanto tecnológicas (GOMES, 2016).

O uso dessas tecnologias pelas crianças, para o desenvolvimento de diferentes aprendizagens, como as de leitura e escrita, é, portanto, defendido por diferentes pesquisadores, como Amante (2007), para quem as TICs possibilitam o desenvolvimento do letramento infantil de forma global e funcionalmente significativa.

Nessa mesma direção, Gomes (2016) defende que as TICs proporcionam oportunidades de aprendizagem mais dinâmicas e mais democráticas, favorecendo o aprendizado colaborativo em ambientes informais ou formais de ensino. Entende-se, a partir disso, que cabe a todos os adultos que convivem com a criança conhecer e compreender a linguagem digital, mediando o uso construtivo. Porém, Gomes (2016) atribui à escola, espaço favorável à vivência lúdica, por meio de brincadeiras coletivas com o uso de ferramentas digitais, o dever de despertar o estudante para o uso crítico e ativo das TICs já na educação infantil, sugerindo os projetos coletivos de aprendizagem de interesse das crianças. Ela alerta para o fato de o domínio das TICs ser, hoje, determinante para o desenvolvimento pessoal e profissional do cidadão. Nesse sentido, Ribeiro (2016) apresenta o conceito de cibercidadão como aquele que, além de ser alfabetizado, é capaz de ler e escrever de modo frequente e competente, construindo sentidos por meio dessas práticas em ambientes não só analógicos, mas também digitais. Em outras palavras, o cibercidadão precisa desenvolver habilidades próprias dos letramentos digitais, "que envolvem inúmeras práticas sociais e concepções para se poder realizar pesquisas na internet, acessar links de navegação, avaliar a credibilidade das fontes, compreender e produzir gêneros multimidiáticos, dentre outras" (RIBEIRO, 2016, p. 163).

Ao falar em ludicidade, Coscarelli (2017) apresenta sugestão de sites em que as crianças aprendem, por meio da brincadeira, a controlar o mouse, digitar, reconhecer signos, palavras, cantar, ouvir e interpretar paródias e histórias. Ela ressalta os sites da autora Angela Lago, cujas brincadeiras levam a criança a interagir e aprender a ler. São exemplos o $A B C D$ da Angela, $A$ cantilena do sapo e História para dormir mais cedo. 
As pesquisadoras Amante e Faria (2012) trazem como exemplo a plataforma Da janela do meu jardim. Criada em 2007 com o objetivo de desenvolver a autonomia e a construção social e pessoal da criança, essa plataforma necessita da presença de um mediador (educador e/ou familiar). Está integrada ao recurso 2.0 da Web e é uma ferramenta que envolve a criança na idade pré-escolar em um ambiente interativo por meio de um contato multimodal com diferentes suportes de comunicação e expressão, fazendo com que desenvolva o pensamento crítico e habilidades para a alfabetização, bem como 0 aprimoramento para o aprendizado da leitura e da escrita.

Aplicativos para smartphones e tablets, segundo Gomes (2016), além de divertir, contribuem com o processo de alfabetização. A autora cita Histórias de embalar, que veicula clássicos infantis em forma de livro com áudio e desenhos, disponível em iOS e Android. E Doki: explorando o oceano, livro interativo da LivoBooks em parceria com a Discovery Kids, disponível em plataforma iPad. Mas alerta que cabe a pais e professores o incentivo ao uso de programas, jogos e aplicativos de qualidade, bem como a testagem da "qualidade pedagógica dos programas a partir de alguns indicadores, entre eles, objetivo, valor cultural, classificação etária" (GOMES, 2016, p. 155).

Há, ainda, uma diversidade de plataformas para leitura em meios digitais, como as bibliotecas Elefante Letrado, Bamboleio e Leiturinha Digital. Todas apresentam um acervo de literatura infantil selecionado por especialistas. Constituem-se em um ambiente lúdico e interativo, mas também de aprendizado, desenvolvimento da autonomia e momentos de criação de laços com os cuidadores. Podem ser assinadas por escolas ou pela família. Essas bibliotecas digitais permitem a disseminação da literatura infantil e o desenvolvimento do hábito de ler, além de incentivarem a mediação de leitura. Também, há plataformas de leitura e autoria para crianças, como a Inventateca, por meio da qual o usuário pode criar várias versões para uma mesma história, permitindo compartilhá-las e até divulgá-las em livro impresso.

Também interessa a visão de Ribeiro (2016), que estudou como alguns jogos digitais são executados e o que o jogador aprende com eles, conferindo a essa ferramenta 0 status de recurso de ensino-aprendizagem. A autora apresenta possibilidades e alternativas para o trabalho docente com esse material a fim de que sejam desenvolvidas as habilidades de leitura e escrita dos estudantes. Ela afirma que a sociedade contemporânea está continuamente lendo/teclando/escrevendo, para estabelecer interação on-line com pares. Entretanto, avalia como ainda pouco produtivo o cenário da incorporação das TICs nos ambientes educacionais porque docentes de diferentes níveis de ensino apresentam dúvidas e dificuldades no uso dessas tecnologias como recursos pedagógicos. Número considerável, 
segundo a autora, não consegue ir além do uso de recursos multimidiáticos como meros acessórios para as aulas.

Ribeiro (2016) constata que esses jogos digitais, com ou sem fins didáticos, tornam o processo de aquisição da escrita mais motivador, dinâmico e lúdico e não deveriam ser deixados de lado por professores de língua portuguesa inclusive dos anos finais do ensino fundamental e do ensino médio. Ela justifica esse ponto de vista explicando que o jogo digital on-line é multimodal, cabendo ao jogador perceber como as diferentes linguagens/signos que o constituem se organizam e se integram para produzir sentidos. Esclarece que o jogador precisa compreender as regras do jogo e como operá-las por meio do manuseio de botões, janelas, abas, ícones, links etc., identificando os limites e as possibilidades do jogo. Essa interação permite a elevação do grau de letramento digital na medida em que o jogador é levado a refletir sobre o uso de cada um desses elementos e é habilitado a utilizar novas interfaces, participando de outras práticas sociais em rede. A pesquisadora mostra o exemplo do site Escola Games, indicado para crianças a partir de 5 anos, no qual é possível encontrar, por exemplo, o jogo Brincando com as vogais, cujo intuito é o de auxiliar no processo de alfabetização.

Para dar continuidade ao processo de alfabetização digital, Lorenzi e Pádua (2012) afirmam que, para a formação de um leitor proficiente, um dos principais focos é o ensino da língua portuguesa em conjunto com os multiletramentos. Assim é possível explorar novas habilidades exigidas pelos suportes digitais, fazendo uso das multimídias e dos hipertextos desde os anos iniciais para desenvolver nas crianças as capacidades de comunicação, de escrita e de leitura do conteúdo aplicado.

Para sustentar esse ponto de vista, Lorenzi e Pádua (2012) apresentam uma sequência didática em que crianças do $1^{\circ}$ e $2^{\circ}$ anos do ensino fundamental I construíram um blog. Para desenvolver esse projeto, foi estimulada a pesquisa por meio de perguntas, para saber se os alunos sabiam o que era um blog, quais recursos se utilizam para criar um, bem como qual a finalidade dele. As autoras escolheram temas que atraem a atenção das crianças, como clássicos da Disney, e mostraram imagens conhecidas de filmes como Branca de Neve e Cinderela. Primeiro analisaram imagens desses clássicos, fazendo uma leitura visual, e depois produziram o blog. É possível observar que essa atividade busca inserir os estudantes em práticas sociais reais de leitura e escrita.

Os exemplos levantados evidenciam que é variada a opção de ferramentas digitais à disposição das crianças e adolescentes para interação social. Além do blog e dos jogos on-line, Santos e Silva (2019) lembram os e-mails, fóruns de interação e discussão, bem como chats das redes sociais. Os materiais digitais propiciam novas formas de aprender e devem ser usados para qualificar o processo de formação de leitores proficientes, desde a infância, dentro e fora da escola. 


\section{Considerações finais}

A formação leitora iniciada na infância, mesmo antes de a criança ingressar na escola ou estar alfabetizada, pode contribuir com o desenvolvimento do jovem leitor interessado por essa prática social e capaz de realizá-la com proficiência em diferentes situações de interação em sociedade. Entende-se, portanto, que a iniciação da leitura deve ocorrer em casa, inclusive antes de a criança pronunciar as primeiras palavras, para isso, deve haver participação dos pais e familiares, os primeiros mediadores e incentivadores desse processo. Considerando o amplo acesso da criança a tecnologias digitais, o incentivo à leitura pode ser potencializado com o uso de aplicativos digitais, com músicas e histórias infantis; jogos visualmente atraentes, com fotos de objetos e animais que auxiliam a descoberta de cores, movimentos e palavras, com a possibilidade de desenhar, montar personagens, bem como desenvolver a imaginação por meio da criação de histórias e canções. Essas atividades configuram a promoção dos multiletramentos, considerando o acesso da criança a práticas de leitura e escrita multimodal e manuseio das ferramentas tecnológicas.

O aprendizado da leitura, antes condicionado somente à identificação de letras impressas, atualmente está também vinculado ao espaço multimidiático e multissemiótico. Ler é um movimento de interação com o mundo, com a evolução das tecnologias digitais, as diferentes formas de interagir com os textos condicionam a construção de sentidos e fazem parte da vida cotidiana das pessoas. Nesse contexto, tecnologias analógicas e digitais não são excludentes, mas coexistem no processo de aquisição e desenvolvimento das práticas de leitura e escrita.

O papel da escola, nesse processo, conforme Xavier (2011), é de se atualizar e ofertar condições mínimas para que estudantes e professores tenham acesso às tecnologias digitais, principalmente, se consideramos que muitos discentes ainda não dispõem dessas ferramentas no meio familiar. Portanto, as instituições de ensino precisam estar constantemente atualizadas e viabilizar as ações pedagógicas necessárias para inclusão digital dos educandos. Além disso, é necessário ressaltar que as tecnologias digitais devem ser vistas como ferramentas, não como protagonistas no processo, ou seja, o professor precisa conhecer as diversas possibilidades de trabalho com tecnologias analógicas e digitais, assim, poderá adotar procedimentos que potencializarão a aprendizagem dos estudantes. O papel do professor é fundamental, pois a mediação das práticas linguísticas independe do meio escolhido. Dessa forma, para futuras pesquisas, seria interessante investigar como ocorre a mediação de leitura na educação infantil e anos iniciais do ensino fundamental, se há o uso de tecnologias digitais e como as instituições de ensino dão suporte a esse processo. 


\section{Referências}

AMANTE, L. As TIC na Escola e no Jardim de Infância: motivos e factores para sua integração. Sísifo Revista de Ciências da Educação, Lisboa, n. 3, p. 51-64, 2007. Disponível em: http://sisifo.ie.ulisboa.pt/index.php/sisifo/article/view/61/78. Acesso em: 9 set. 2021.

AMANTE, L.; FARIA, A. Sentido(s) emergente(s) das tecnologias digitais no jardim de infância. In: MOREIRA, J. A.; MONTEIRO, A. (Org.). Ensinar e aprender online com tecnologias digitais: abordagens teóricas e metodológicas. Porto: Porto Editora, 2012.

BRASIL. INAF Brasil 2018: resultados preliminares. Instituto Paulo Montenegro; Ação Educativa, 2018. Disponível em: https://drive.google.com/file/d/1ez-6jrlrRRUm9JJ3MkwxEUffltjCTEI6/view. Acesso em: 7 set. 2021.

BRASIL. INSTITUTO NACIONAL DE ESTUDOS E PESQUISAS EDUCACIONAIS ANÍSIO TEIXEIRA. Brasil no Pisa 2018 [recurso eletrônico]. Brasília: Instituto Nacional de Estudos e Pesquisas Educacionais Anísio Teixeira, 2020. Disponível em: https://download.inep.gov.br/publicacoes/institucionais/avaliacoes_e_exames_da_educacao_basica/rel atorio_brasil_no_pisa_2018.pdf. Acesso em: 7 set. 2021.

CHARTIER, R. A aventura do livro: do leitor ao navegador - conversações com Jean Lebrun / Roger Chartier. Tradução de Reginaldo Carmello de Moraes. São Paulo: Imprensa Oficial do Estado de São Paulo; Editora Unesp, 1998.

COSCARELLI, C. V. (Org.). Letramento Digital. Belo Horizonte: Autêntica Editora, 2017.

DELL'ISOLA, R. L. P. Leitura: inferências e contexto sociocultural. Belo Horizonte: Formato Editorial, 2001.

FOUCAMBERT, J. Modos de Ser Leitor: Aprendizagem e Ensino da Leitura no Ensino Fundamental. Tradução de Lúcia P. Cherem e Suzete Bornatto. Curitiba: Editora UFPR, 2014.

FREIRE, P. A importância do ato de ler. São Paulo: Cortez, 2011.

GOMES, S. D. S. Infância e Tecnologia. In: COSCARELLI, C. V. (Org). Tecnologias para aprender. São Paulo: Parábola Editorial, 2016.

KOCH, I. V.; ELIAS, V. M. Ler e compreender: os sentidos do texto. São Paulo: Contexto, 2006.

LEAL, T. F.; SILVA, A da. Brincando, as crianças aprendem a falar e a pensar sobre a língua. In: BRANDÃO. A. C. P.; ROSA, E. C. de S. (Org.). Ler e Escrever na Educação Infantil: discutindo práticas pedagógicas. Belo Horizonte: Editora Autêntica, 2018.

LORENZI, G. C. C.; PÁDUA, T. R. W. Blog nos Anos Iniciais do Fundamental I. In: ROJO, R.; MOURA, E. (Org.). Multiletramentos na Escola. São Paulo: Parábola Editorial, 2012.

MARTINS, M. H. O que é leitura. 3. reimpr. 19. ed. São Paulo: Brasiliense, 2012. 
PEREIRA, J. T. Educação e Sociedade da Informação. In: COSCARELLI, C.; RIBEIRO, Ana Elisa (Org.). Letramento digital: aspectos sociais e possibilidades pedagógicas. 3. ed. 1 reimp. Belo Horizonte: Ceale; Autêntica Editora, 2014. E-Book.

RIBEIRO, A. E. Texto e leitura hipertextual: novos produtos, velhos processos. Linguagem \& Ensino, v. 9, n. 2, $\quad$ p. $\quad 15-32$, jul./dez. 2006. Disponível em: http://leffa.pro.br/tela4/Textos/Textos/Revista/edicoes/v9n2/01Ribeiro.pdf. Acesso em: 7 set. 2021. HTTPS://DOI.ORG/10.15210/RLE.V912.15637

RIBEIRO, A. L. Jogos on-line ensino-aprendizagem da leitura e da escrita. In: COSCARELLI, C. V. (Org). Tecnologias para aprender. São Paulo: Parábola Editorial, 2016.

ROJO, R. Alfabetização e letramentos múltiplos: como alfabetizar letrando? In: RANGEL, E. de O.; ROJO, R. (Coord.). Língua Portuguesa: ensino fundamental. Brasília: Ministério da Educação, Secretaria de Educação Básica, 2010.

SANTOS, L. V. A.; SILVA, E. P. Leitura e Escrita: a subjetividade na abordagem da prática nos anos iniciais da educação básica. Curitiba: Appris, 2019.

SENHORINI, M.; BORTOLIN S. Bebeteca: uma maternidade de leitores. Informação e Informação, Londrina, v. $13, \quad$ n. 1, p. 123-139, jan./jul. 2008. Disponível em: http://riut.utfpr.edu.br/jspui/bitstream/1/47/4/INF.\%20INF._Senhorini\%2c\%20Mariana_2008.pdf. Acesso em: 7 set. 2021. http://dx.doi.org/10.5433/1981-8920.2008v13n1p123

SOARES, M. Alfabetização e Letramento. São Paulo: Contexto, 2020.

SOCIEDADE BRASILEIRA DE PEDIATRIA. OMS divulga orientações para uso de telas digitais na infância. 2019. Disponivel em: https://www.sbp.com.br/imprensa/detalhe/nid/oms-divulga-orientacoespara-uso-de-telas-digitais-na-infancia/. Acesso em: 7 set. 2021.

SOLÉ, I. Estratégias de Leitura. São Paulo: Penso Editora Ltda, 1998.

SOUZA, H. D. S. C.; SERAFIM, M. S. A Mediação da Leitura na educação infantil: onde a leitura de mundo precede a leitura das palavras. In: BORTONI-RICARDO, S. M. et al. (Org.). Leitura e mediação pedagógica. São Paulo: Parábola Editorial, 2012.

XAVIER, A. C. Letramento digital: impactos das tecnologias na aprendizagem da Geração Y. Calidoscópio, v. 9, n. 1, p. 3-14, jan./abr. 2011. Disponível em: https://www.professores.uff.br/screspo/wpcontent/uploads/sites/127/2017/09/PSI_P2_artigo8.pdf. Acesso em: 7 set. 2021. http://dx.doi.org/10.4013/cld.2011.91.01

Data de submissão: 11/09/2021. Data de aprovação: 26/10/2021. 